\title{
Understanding Social Support Throughout the Injury Process Among Interuniversity Swimmers
}

\author{
Alisa Abgarov, Sarah Jeffery-Tosoni, Joseph Baker, \\ and Jessica Fraser-Thomas \\ York University
}

\begin{abstract}
The purpose of this study was to gain comprehensive understanding of athletes' social support experiences during the injury process, with a focus on social support networks, exchanges, and appraisals (Bianco \& Eklund, 2001). Twelve university swimmers who recently experienced swimming-related injuries engaged in a semistructured interview. Findings indicate athletes had mixed experiences with their networks of social support (i.e., coaches, medical practitioners, parents, and teammates), with themes regarding exchanges and appraisals emerging in three categories: (a) Don't bring your negative energy to practice, (b) Show me you care, and (c) Provide me with some clear and appropriate direction! Participants reported coaches and teammates being in denial of their injuries, shunning them from the team, or pushing them to train through their injuries, resulting in athletes feeling uncared for, unsupported, and lacking direction. Athletes' sense of support stemmed from feeling cared for. Findings underscore the importance of comprehensively examining the multiple constructs of social support, while serving as a springboard for further investigations and important practical implications.
\end{abstract}

Keywords: injury rehabilitation, university, swimming, social support

In Canada, over 4.3 million (approximately 15\%) Canadians aged 12 and older suffer an activity-limiting injury each year, with the most common cause of these injuries being sport/physical exercise (Statistics Canada, 2010). In intercollegiate sport contexts, Hootman et al. (2007) reported 182,000 injuries (i.e., that required medical attention and at least one day of time lost) in the NCAA over a 16-year period (from 1988 to 1989 through 2003-2004), a mean of over 11,000 injuries per year. Injury and return to sport following injury is often stressful and emotional for athletes. Past studies suggest that athletes experience extensive emotional challenges throughout injury, including feelings of loss, fear, anxiety, lack of confidence, decreased self-esteem, increased stress, loss of identity, intrusive thoughts, avoidance behavior, denial, anger, frustration, and depression (Appaneal, Perna, \& Larkin, 2007; Newcomer \& Perna, 2003; Tracey, 2003). Social support has

The authors are with the School of Kinesiology and Health Science, Norman Bethune College, York University, Toronto, Ontario, Canada. 
the potential to play an important role in athletes' ability to cope emotionally with their injury and the injury rehabilitation process, relieving athletes from distress and enhancing their coping mechanisms throughout the injury process (Bricker \& Fry, 2006; Tracey 2011; Udry, 1997).

Despite this, very little is known about how social support is provided to these athletes throughout their injury rehabilitation. As such, the purpose of this study is to explore the social support collegiate athletes receive when they are injured. Specifically, we focus on who provides support for injured athletes, the nature of the support, and how the athletes interpret this behavior.

\section{Theoretical Framework}

Social support is broadly defined as social interactions aimed at inducing positive outcomes (Bianco \& Eklund, 2001). Vaux (1988) proposed that social support is a multiconstruct comprised of three main subconstructs: (a) structural features (i.e., networks), (b) functional features (i.e., exchanges), and (c) perceptual features (i.e., appraisals). With regard to support networks, past work has suggested that different individuals within social support networks may play different roles depending on their closeness to the individual (Lin, 1986). Hardy and Crace's (1993) typology organizes social support exchanges into three main categories: (a) emotional support may include listening and comforting, (b) information support could include discussing and acknowledging an injured athlete's status, and (c) tangible support, may come in the form of providing personal or material assistance. Social support appraisals have been found to be of particular importance given that recipients' perceptions of support behaviors are often more reliably associated with their positive health outcomes than objectively measured support behaviors (Schwarzer \& Leppin, 1991). As such, Shumaker and Bromnell's (1984) definition of social support, emphasizing that a social support activity involve the intent to help another, but may in fact fail to do so, is of particular relevance. Sarason, Sarason, and Pierce (1994) also acknowledge the important interactive component of social support, suggesting social support is influenced by the sociocultural context, the provider and recipient characteristics, and the relationship characteristics of the provider and recipient. Bianco and Eklund's (2001) conceptual map of the social support process integrates the tenants previously outlined, suggesting that structural, functional, and perceptual features of social support, as influenced by sociocultural context, provider and recipient characteristics, and relationship characteristics play an important role in facilitating positive health outcomes such as injury rehabilitation and return to sport.

While the three constructs of social support networks, exchanges, and appraisals are certainly interconnected, much of the social support research has focused on examining them independently. To fully understand the mechanisms and processes underlying effective social support throughout the injury process, it is essential to examine these constructs simultaneously. Thus, in drawing from our review of social support theory, the overall purpose of this study was to gain comprehensive understanding of injured athletes' social support experiences during the injury process. More specifically, we focused on understanding social support networks, social support exchanges, and social support appraisals. 
Canadian university sport offers a unique sociocultural context to examine these research questions, given that university athletes are required to demonstrate high levels of commitment to their training and competition while meeting extensive academic demands. The sport of swimming is of particular interest, given it is one of the most popular sports in Canada (Clark, 2009), and carries a relatively high incidence of gradual onset overuse injuries (Brushoj, Bak Johannsen, \& Fauno, 2007; McMaster, 1996). Prolonged periods of rehabilitation and recovery have the potential to further amplify the important role of social support in the injury process. Further, the characteristics of and relationships with social support providers (i.e., parents, peers, partners, other adult models) are considered of particular importance during this transitional period of emerging adulthood (Arnett, 2000).

The following research questions helped guide the analyses:

RQ1: Who is providing social support for athletes who sustain an injury?

RQ2: What behaviors are demonstrated to support athletes who sustain an injury?

RQ3: How do athletes who sustain an injury interpret these behaviors?

\section{Method}

\section{Participants}

Participants included 12 current or recently graduated (i.e., within 3 years) university student-athletes who self-identified as sustaining a swimming-related injury during their interuniversity swimming career. A 3-year interval since the occurrence of the injury was used as screening criteria to assure all participants had been involved during a similar time period, and to reduce the effects of forgetting or biasing the experience in the long-term memory. Past research on recall of sport experience found a two-year window provided effective recall of experiences (Law, Côté, \& Ericsson, 2007), while researches have observed lower validity and reliability of information after five years (Ropponen, Levalahtti, Simonen, Videman, \& Battie, 2001).

Participants were purposefully sampled (Patton, 2002) to capture diverse backgrounds (i.e., participants of mixed genders, ages, abilities and specialties, from different university teams in different provinces, and with different injuries). As such, participants included 5 females and 7 males ages 20-28 from interuniversity swimming programs in the provinces of Ontario and Quebec, Canada; 5 were currently swimming at a provincial level, 6 at a national level, and 1 at an international level. Given the context of this study, some key points regarding interuniversity sport programs in Canada are noteworthy. First, while athletic scholarships are available, they are not widely distributed, and offered to a maximum amount of tuition and compulsory fees (i.e., approximately $\$ 5,000-\$ 8,000$ per year). As such, athletic scholarships were not considered a substantive influence in the experiences of participants in the current study and none of the 12 participants were receiving athletic scholarships at the time of data collection. Second, Canadian interuniversity sport programs are often not fully supported financially, with many head and assistant coaches working as volunteers, or for an honorarium rather than a salary. 
Third, most university swimming teams have an athletic therapist on staff, who is often a university student trainee, but rarely have any other medical professionals directly affiliated with the team. Finally, most intercollegiate sports including swimming begin in September and conclude with the national championships in early March (the academic calendar year ends in April); as such many swimmers train year round, but compete for only a six-month season.

In the current study, 6 of the 12 athletes had a history of swimming-related injury before their interuniversity sport involvement, while 6 incurred swimmingrelated injuries for the first time during their university involvement. Most of the participants $(n=10)$ experienced multiple injuries throughout their university swimming career. Shoulder injuries were most common, experienced by 11 of the 12 participants; other injuries included knee, back, groin, elbow, ankle and hip injuries. At the time of data collection, participants' reported injury durations from approximately 3 months to 6 years; 10 participants discussed having injury relapses and/or ongoing pain related to their injuries, while 2 participants outlined that their injuries were resolved. Given that all athletes experienced gradual onset injuries, the specific length of time since injury occurrence was not measured. None of the participants had undergone surgery for their swimming-related injuries. Participants' current swimming involvement was mixed: some stopped before graduation due to injuries, some stopped at the time of graduation, while others were continuing to swim with their university team or a master's team.

\section{Data Collection}

We recruited participants through their involvement in a previous study of trends and risk factors of swimming-related injuries in university swimmers (Abgarov, Fraser-Thomas, \& Baker, 2012), as well as our contacts within the swimming community in Canada. Before data collection, participants read and signed the informed consent form, and completed a short questionnaire to identify background information and eligibility screening. Participants then engaged in a 45-90 minute in-depth semistructured interview with the primary researcher. The interview questions focused in five areas: (a) swimming and injury history, (b) experiences during the injury process, (c) experiences interacting with networks of social support during the injury process, (d) coping strategies throughout the injury process, (e) current sport and physical activity participation. All interviews were conducted face to face in a quiet, comfortable environment chosen by the participant. Interviews were digitally recorded and transcribed verbatim. Once transcription was complete, participants reviewed their transcripts for verification, and were given the opportunity to add, delete, or rephrase their responses to assure that responses reflected their intended communications. Before beginning data collection, the research protocol was reviewed and approved by the Human Participants Research Committee (HPRC) of the affiliated university.

\section{Data Analysis}

The data underwent qualitative analysis using the constant comparative method, a component of the grounded theory approach (Charmaz, 2006; Corbin \& Strauss, 2008). First, the transcripts were read and reread in order for the researchers to become familiar with the data. The researchers then coded meaningful units of 
information within the data, applying tags, which identified ideas, concepts, terms, and phrases emerging from the data. Next, open coding was used to categorize similar and different meaning units into themes, using assigned tags. Finally, axial coding was used to establish connections between themes and create categories, based on context, conditions, actions, and events being explored. Throughout the process, researchers engaged in constant discussions to assure tagging of meaning units, groupings of themes, and establishment of categories offered an appropriate representation of the data; these discussions led to some reanalysis as appropriate.

The trustworthiness of the data collection and analysis was assured through a number of means. First, data collected in the previous study (Abgarov et al., 2012) provided background information (i.e., age, swimming milestones, injury history) that offered context when asking interview questions. Second, several probing questions were used throughout the interview to provide the participant every opportunity to clearly communicate his/her meaning. Sample probes included: "Why?" "How did that happen?" "How did you feel about X?" "What do you mean by X?" Third, as previously outlined, participants had the opportunity to review their transcripts to assure they reflected their intended communications. Fourth, also outlined above, a maximal 3-year interval since the occurrence of the injury minimized the effects of forgetting and biasing the experience in the long-term memory (Law et al., 2007; Ropponen et al., 2001). Finally, during the analysis phase, the consistency of the meaning units was verified in a random sample of meaning units, where two independent researchers assigned themes and categories to the selected meaning units. Interrater reliability was very high $(88 \%)$.

\section{Results and Discussion}

The overall purpose of this study was to gain comprehensive understanding of injured athletes' social support experiences during the injury process, with a particular focus on social support networks, exchanges, and appraisals, within the context of Canadian university swimming. Findings indicate swimmers' networks of social support consisted of four key groups of individuals: coaches (i.e., head and assistant), medical practitioners (i.e., family physicians, physiotherapists, massage therapists, athletic therapists, chiropractors, acupuncturists, and sports medicine specialists) parents, and teammates. Athletes spoke of very mixed experiences with these individuals, often struggling to understanding why key members of their social support networks behaved in certain ways. Findings relating to exchanges and appraisals emerged in three key categories: (a) Don't bring your negative energy to practice (5 themes) (b) Show me you care (7 themes), and (c) Provide me with some clear and appropriate direction ( 5 themes); see Table 1 . The number of participants who discussed each theme is also outlined in Table 1; this information was included to enhance understanding of the similarities and differences of participants' experiences, in addition to demonstrating the amount of evidence for each particular theme (Miles \& Huberman, 1994). This information was also thought relevant given that in many cases, individuals had multiple distinct injury experiences within their university swimming career, which in some cases resulted in the same athlete having multiple diverse injury experiences. In each of the quotations, we identify participants by their participant number, gender, and age (e.g., participant 11, a female aged 24, is identified as P11, F-24). 


\section{Table 1 Social Support Exchanges and Appraisals Throughout the Injury Process: Categories and Themes}

\begin{tabular}{|c|c|c|}
\hline Category & Theme & $N$ \\
\hline \multirow{5}{*}{$\begin{array}{l}\text { 1. Don't bring your negative } \\
\text { energy to practice. }\end{array}$} & 1. Coaches were in denial of athletes' injuries. & 10 \\
\hline & $\begin{array}{l}\text { 2. Athletes hesitated to communicate with coaches } \\
\text { regarding their injury. }\end{array}$ & 8 \\
\hline & 3. Athletes felt unsupported by coaches. & 3 \\
\hline & $\begin{array}{l}\text { 4. Athletes felt teammates did not "believe" they were } \\
\text { injured. }\end{array}$ & 8 \\
\hline & $\begin{array}{l}\text { 5. Injury created void in athletes' relationships with } \\
\text { teammates. }\end{array}$ & 7 \\
\hline \multirow[t]{7}{*}{ 2. Show me you care. } & 1. Coaches showed they cared. & 8 \\
\hline & 2. Teammates showed they cared. & 3 \\
\hline & 3. Other injured teammates showed they cared. & 2 \\
\hline & 4. Parents showed they cared. & 5 \\
\hline & 5. Parents were uninvolved. & 3 \\
\hline & 6. Medical practitioners showed they cared. & 3 \\
\hline & 7. Medical professionals were not caring. & 5 \\
\hline \multirow[t]{5}{*}{$\begin{array}{l}\text { 3. Provide some clear and } \\
\text { appropriate direction! }\end{array}$} & $\begin{array}{l}\text { 1. Coaches failed to provide appropriate training modi- } \\
\text { fications. }\end{array}$ & 5 \\
\hline & 2. Coaches facilitated appropriate training modifications. & 7 \\
\hline & $\begin{array}{l}\text { 3. Athletes did not feel medical professionals were } \\
\text { knowledgeable. }\end{array}$ & 1 \\
\hline & $\begin{array}{l}\text { 4. Athletes felt medical professionals were knowledge- } \\
\text { able. }\end{array}$ & 5 \\
\hline & 5. Athletes felt conflicted by opposing recommendations. & 5 \\
\hline
\end{tabular}

Note. $N$ represents number of participants that discussed a theme.

\section{Don't Bring Your Negative Energy to Practice}

One of the most concerning findings of this study relates to athletes' lack of support from coaches and teammates during the injury process. This lack of support was demonstrated in various means including resisting acknowledgment of the injury, isolating the injured athlete, or even shunning the athlete from the team once their injury was acknowledged. These concerning findings are outlined in the five themes discussed below.

Coaches Were in Denial of Athletes' Injuries. Throughout their interviews, many athletes $(n=10)$ suggested coaches seemed in denial of their injuries. This was evident through coaches' resistance to acknowledge injuries: "He didn't want to hear about it. He knew that I was injured and he wanted me to get over it, and I couldn't" (P4, M-28). Coaches were also reported to push athletes to continue training and competing, while ignoring the physical limitations of athletes' injuries 
and suggesting that pain is a "normal' part of training and fatigue. The following conversation with a participant (P11, F-24) captures this situation:

Researcher: What did your coach do if you said you could not do it?

P11: He'd tell me to try and if I'm not able, if I'm really, really, really not able to do it, I could stop. But only if I'm really not able to continue, and not just if I just feel pain.

Researcher: So what did you do?

P11: I continued, until I cried, and then I got out [of the water]. (Tearful).

Researcher: How did you feel at that time?

P11: Depressed. I was angry with the coach.

Researcher: Why?

P-11: Because he asked me to continue, even though I was not able to, and I didn't feel like I could stop until I needed help to get out of the pool. I felt like I could not stop. He made me feel like-if I don't have to go to the hospital, I don't feel enough pain to stop.

It is alarming that coaches appeared in denial of athletes' injuries, and often pushed them to continue training despite all the signs and symptoms of injury. While past work suggests coaches believe athletes should push themselves to their physical limits (Nixon, 1994), the context of university sport may accentuate this situation given coaches are highly invested in the outcome of a short season. Further, the sport of swimming may have also heightened these effects, given the high prevalence of gradual onset and/or overuse injuries (Abgarov et al., 2012; Flint, 1998); pushing through such injuries may be considered essential so as not to lose the entire competitive season. While future research is warranted, coaches should be cautious not to communicate a risk-pain-injury paradox, which may in turn contribute to athletes' normalization of pain and pushing through injury (Young, White, \& McTeer, 1994).

Athletes Hesitated to Communicate With Coaches Regarding Their Injury. Given many coaches' initial response to athletes' injuries, it is not surprising that many athletes $(n=8)$ discussed being hesitant to communicate with their coaches regarding their injury. Many spent a significant amount of time evaluating and assessing their pain before approaching their coach. As one athlete outlined, "I would have to make sure that it was actually legitimate pain, and then I would let [the coaches] know" (P5, F-24). Others appeared to make a deliberate effort not to show their injury-related frustrations to coaches. As one athlete said, "[Coach] knew that my shoulder was messed up, but I thought I had to swim or I'd be letting him down and letting myself down" (P11, F-24). Another said, "I guess I could probably have shared [my emotions] with them more, but I always felt that they were too busy. They had too much going on, and I didn't want to bother them" (P1, F-24).

Athletes Felt Unsupported by Coaches. Some athletes $(n=3)$ did communicate openly with their coaches, but felt unsupported when they opened this line of communication. Specifically, three of the athletes spoke of feeling overlooked, 
misunderstood, pushed aside, and undervalued. One swimmer actually outlined a coach's policy regarding injured athletes:

We have a rule now: If you're injured and you are not swimming, then you kinda stay away from the team. It's not like to push you out, but if other swimmers see you on the deck, they might get the feeling that you are not actually hurt-that you just don't want to practice. So [the coaches] try to help you, but there is only a certain amount that they can do. (P6, M-21)

Athletes Felt Teammates Did Not "Believe"They Were Injured. In line with the coach policy described above, several athletes $(n=8)$ suggested they did not feel their teammates "believed" that they were injured, but thought instead that they wanted a break from training. For this, they felt judged.

It sucked seeing everyone else swim and being on the side doing dry land. I tried to prove myself. I did tons of dry land and core and always tried to find something to keep myself busy with. But I know that some people were judging me thinking I was just sitting on the side and doing nothing. (P7, F-20)

One participant also emphasized the emotional toll of her experiences with teammates:

The first word that comes in mind is "draining." It is actually draining. You're always scared what people think about you. You always think they think that you don't work hard enough. You always worry. The whole time that it hurt, you worry what everyone else thinks. "Do you think I'm this?" Or, "Do you think I'm that?" Whatever. The whole thing is worry, worry, worry. (P8, F-24)

Injury Created a Void in Athletes' Relationships With Teammates. Given participants' perceived breakdown in trust and honesty between injured athletes and their teammates, it follows that their injury led to altered relationships with teammates $(n=7)$. As one participant outlined, "As soon as you get out [of the water], you feel like you are not as much a part of the team" (P7, F-20). Others spoke of struggling to maintain a "normal" communication with teammates, because the injury consumed their lives, but teammates tired of hearing about it:

They obviously know that I don't like [being injured]. But I don't like to cry about things. I don't like to be, "Ooh it hurts." I mean, they know it sucks for me. But for someone to just keep saying [it hurts], is like, "Okay, be quiet." (P6, M-21)

Prior research suggests athletes' injury experiences may lead to feelings of fear, anxiety, lack of confidence, stress, denial, and depression (Appaneal, et al., 2007; Newcomer \& Perna, 2003), and that athletes often experience feelings of separation, loneliness, guilt, and loss of identity because they are no longer vitally contributing to the team (Lewis-Griffith, 1982). Findings of this study suggest teammates may be further contributing to negative emotions through their mistrust and failure to act in an empathetic manner, at a time when athletes are experiencing their greatest need for support from these individuals (Yang, Peek-Asa, Lowe, Heiden, \& Foster, 2010). 
Collectively, the aforementioned findings suggest athletes had several concerning experiences with coaches and teammates, leading them to feel unwelcome at practice, due to the negative energy they brought with them. One can only assume that it was not the intent of coaches and teammates to demonstrate such nonsupportive behaviors toward injured athletes, yet this was clearly the resulting consequence. These findings reaffirm the importance of Shumaker and Bromwell's (1984) definition of social support, focused on an individual's intent to help another, while acknowledging individuals may in fact fail to do so. Further, these findings highlight the importance of investigating the interdependent features of social support (Winemiller, Mitchell, Sutcliff, \& Cline, 1993), as findings suggest injured athletes' appraisals of their exchanges with support networks during the injury process hold significant weight. While this study offered rich detailed and honest accounts of injured athletes' experiences, future researchers may expand on these findings by gleaning the perspectives of members of support networks themselves and the roles they feel they play throughout athletes' injury processes.

\section{Show Me You Care}

The second category related to exchanges and appraisals emerging from the data were related to caring. Participants consistently discussed the importance of individuals within their networks of support showing that they cared for them not only as performing athletes, but also as healing persons. Athletes recounted several experiences where they felt cared for by critical networks of support, but also shared less positive experiences.

Coaches Showed They Cared. Several athletes $(n=8)$ suggested they had coaches who cared about them throughout the injury processes. In contrast to coaches described above who ignored or denied the presence of an injury, participants described coaches with whom they had open and honest communication. As one athlete stated,

I will go and talk with my coach about stuff. I will go and say that it hurts and it sucks and I cannot do this, and he is, "Okay" and "That's fine." We are pretty tight. He understands that when I tell him that it hurts, I'm not lying to him. I don't say, "Look, it hurts" when it doesn't hurt. (P6, M-21)

Further, other athletes described caring coaches as coaches who listened, understood, encouraged, and appreciated them, while playing an active role in helping them deal with their injuries. As one athlete said, "He was the best coach. He would always listen. He was very understanding and would always go and give me a high five and that was what helped to keep me going... that someone cared" (P7, F-20). These findings compliment past work showing that athletes' injury recovery is facilitated by coaches' interest, reassurance, encouragement, assistance, support, and focus on the future (Bianco, 2001; Gould, Udry, Bridges, \& Beck, 1997).

Teammates Showed They Cared. As highlighted by findings in the previous category, many participants did not feel supported by their teammates. Only three female athletes spoke of feeling cared for by teammates throughout their injury process; they acknowledged their connections were often challenged when they had to take time off, but outlined how their relationships did not falter: 
I found the girls on the swim team were phenomenal. It's another reason you want to keep swimming. I didn't want to be off the team-I love my teammates. They are great. We have a lot of fun, and I didn't want to lose that team atmosphere-being there. They were very supportive of me. Like, "Take a little time" and like, "Cycle for a bit" and that. So they were really good. (P5, F-24)

These findings extend work by Bianco (2001); in addition to suggesting that unconditional care and friendship are beneficial in the injury process, athletes in this study were particularly appreciative of teammates recognizing their injuries as genuine, and continuing to make them feel a part of the team. The finding that only females felt cared for by their teammates is concerning, highlighting a need for future research to understand the complexities of male and female athletes' relationships with their teammates during the injury process.

Other Injured Teammates Showed They Cared. Of particular interest were two female participants who spoke of feeling cared for by a specific group of teammates, all of whom were currently or formerly injured themselves. Participants suggested injured teammates befriended them when they became injured. They appreciated connecting with these individuals, as they related to their situation, and offered constructive advice:

There are a couple of girls on my team that have struggled with bad back injuries over the past few years. One of them in particular-I meet with. We go and have a coffee every so often. I think it's good because through that experience-having that similar experience-we are able to connect. (P1, F-24)

While only two female participants discussed this theme, the finding is unique, and may be a reflection of the untapped potential of a positive resource within athletes' own team environment. This finding aligns with previous work suggesting senior teammates who have successfully endured challenging sport situations (e.g., performance plateau, consideration of dropout) should be paired with younger athletes going through similar situations to discuss shared experiences and optimal strategies to best work through associated physical, psychological, and social obstacles (Fraser-Thomas \& Côté, 2008). Future intervention research should examine the effectiveness of integrating a mentoring program or "buddy system" into injury rehabilitation programs.

Parents Showed They Cared. Participants $(n=5)$ discussed their parents' supportive involvement during their injury experiences. In some cases parents' behaviors were very proactive, involving encouragement, suggestions, and ongoing discussions: "I remember when I was injured it was my mom who actually said, 'you might be able to come back to swimming. It might not be the end.' I didn't want to get my hopes up — to even think like that - but I figured she had a point" (P5, F-24). In other cases, parents' support was more passive and emotionally based, involving sympathy, empathy, and understanding: "They were-you know-I guess disappointed. Not in me, but at the situation. They sympathized with me and I felt that they were supporting me" (P1, F-24). These findings support past work highlighting the importance of family who are positive, optimistic, and unconditionally supportive throughout the injury process (Bianco, 2001), with 
involvement often being primarily passive in the later stages of development (i.e., university level; Côté, 1999; Fraser-Thomas, Côté, \& Deakin, 2008).

Parents Were Uninvolved. In contrast, three male participants spoke of parents' lack of involvement throughout the injury process, but suggested they did not seek any emotional support from their parents: "I keep to myself" (P2, M-26). "I don't like to talk about it. I don't like to complain" (P4, M-28). "I was a standard 24-year old guy (....) I hated involving anyone" (P12, M-28). While past literature suggests females are more likely to seek social support in stressful situations (Ptacek, Smith, \& Dodge, 1994), the current findings indicate a need for further investigation of similarities and differences in how male and female intercollegiate athletes use their networks of social support, particularly family networks, throughout injury.

Medical Practitioners Showed They Cared. A few athletes $(n=3)$ expressed appreciation for medical professionals' support. Most often athletes spoke of physiotherapists or athletic trainers showing that they cared by listening to their concerns, understanding their frustrations, and using their knowledge to help them on their rehabilitation path. As P3 (M-23) stated, "They were quite sympathetic and understanding."

Medical Professionals Were Not Caring. Athletes $(n=5)$ also shared experiences of frustration because they did not feel cared for by medical professionals, suggesting they felt they were a nuisance or bother to the very people who were supposed to be helping them: "[Physio] was too much like a business. You walk in. He hasn't personally seen you. He has two other people there. He hooks you on to the machine. You don't get any one-on-one time with him. It's very impersonal" (P10, M-22). These findings emphasize the value injured athletes place on supportive medical practitioners. Given past work showing athletes who have confidence in medical practitioners are more likely to comply with rehabilitation programs (Bricker \& Fry, 2006; Christakou \& Lavallee, 2009), medical practitioners' strong interpersonal skills and positive relationships with athletes appear essential to athletes' optimal injury process.

Collectively, findings in this category (i.e., show me you care) are of particular interest when examined through the lens of social support network composition. Lin (1986) suggested that close relationships are those that involve a high amount of time spent together, emotional intensity, intimacy, and reciprocity, while more distant relationships involve lower levels of each of these factors. According to social resources theory (Lin, 1986), athletes rely on their closest relations, typically parents and peers, to share feelings and vent frustrations, while relying on more distant relations such as coaches and medical practitioners, to gain information to cope with and address problems. In the context of interuniversity sport, however, when athletes are living away from home, and spending excessive amounts of time training and competing, individuals' closest relationships may in fact be with coaches and teammates. If the individuals with whom injured athletes are most eager to share their emotional struggles (i.e., coaches) are the same individuals who have the most to lose from injured athletes' struggles, this situation may quickly become problematic. Similarly, teammates may be among injured athletes' closest friends, yet are also highly invested competitive athletes, most likely with 
personal agendas involving positive focus rather than support for unhappy teammates. As such, findings of this study reinforce past work (Dakof \& Taylor, 1990) suggesting support within close relationships that involve conflict may not always lead to positive outcomes. Further, while medical practitioners would usually be expected to have fairly distant relationships with athletes, a few athletes spoke of their appreciation for medical practitioners showing care, and a greater number still expressed frustration in medical practitioners' lack of caring behaviors. These findings appear to suggest that athletes sought and valued close relationships with their medical practitioners, in line with past work showing individuals appreciate close ties with those that can help them most in times of crisis (Gordon, Potter, \& Ford, 1998). Finally, while parents would be assumed to be among injured athletes' closest relations, the university context may again have altered this dynamic, as a few participants clearly articulated that they would not seek emotional support from family members.

\section{Provide Some Clear and Appropriate Direction!}

All athletes spoke of having frustrating experiences at some point throughout their injury process regarding the advice they received from individuals within their social support networks. Most often these frustrations related to the specific recommendations provided by coaches and medical practitioners, in addition to the often conflicting nature of these recommendations.

Coaches Failed to Provide Appropriate Training Modifications. Some athletes $(n=5)$ suggested coaches often failed to provide appropriate advice with regard to training modifications, leaving athletes feeling misguided. As one athlete said, "Maybe he didn't know what to do. Maybe he didn't have that much experience with that kind of injury" (P4, M-28). Another described her typical training modification plan, and resulting frustration:

[Coach's] reaction was [for me] to get in and kick, or swim with one arm, or to sit on a bike and spin for 2 hours. I understand now the whole physical fitness aspect of it - of wanting to keep me in shape and keeping me in the habit of getting up early and the team camaraderie and everything like that, but it was really frustrating to just sit there on the bike. (P8, F-24)

Coaches Facilitated Appropriate Training Modifications. In contrast, many athletes $(n=7)$ expressed appreciation of their coach's approach to facilitating training modifications. For example, one participant discussed how her coaches created an environment where she was in control of her training:

My coaches understood. I mean there was nothing they could do. My coaches were a little like-they were not like club coaches that were hovering above you. You know, they were like, "Do your own thing." It's good. It's different but it's good cause they treat you more like an adult. You make your own decisions. I liked them giving the ideas, but sometimes they would say, "Why wouldn't you modify this?" or, "Why won't you modify that?" But ultimately I had to take care of myself. Nobody could do that for me, cause nobody knows when it hurts. (P1, F-24) 
Athletes Did Not Feel Medical Professionals Were Knowledgeable. Athletes also had expectations for direction from medical professionals, but were often disappointed. One third of participants $(n=4)$ did not feel medical professionals demonstrated competence, provided comprehensive treatment, or thoroughly supported them as patients. Sometimes participants believed that medical professionals lacked expertise about their specific injury: "[My] family doctor is too general to even know what he is talking about, so he is pointless to go to" (P7, F-20). Other participants were frustrated by doctors' lack of understanding of the interuniversity sport context, as they simply suggested athletes stop swimming until their injury was completely healed. Participants were particularly disappointed by medical practitioners' common suggestion to use medications to control pain, while failing to provide recommendations on means to heal injuries or prevent injury relapses. As one athlete explained:

I'm thinking that modern medicine is more of a modern chemistry. I don't want you to treat my symptoms - it's pointless. The cause is what is hurting. I don't need anti-inflammatories - maybe I do-but the point is that I also need to treat the injury, because I obviously don't know how to. It hurts and I think that if I stretch, it would be better, but at the end of the day, I don't know. (P11, F-24)

Athletes Felt Medical Professionals Were Knowledgeable. In contrast, some athletes $(n=5)$ reported positive experiences with medical professionals, suggesting they were knowledgeable, helpful and effective. As one athlete highlighted, "The chiro[practor] worked with the Olympic track and field team so he knew what he was doing and I had a lot of confidence [in him]" (P12, M-28). Another athlete outlined, "The sports doctor was really good. He was more interested in treating the problem than the symptoms. He was looking for the cause of the symptoms" (P11, F-24).

Athletes Felt Conflicted by Opposing Recommendations. Athletes $(n=5)$ commonly spoke of receiving conflicting advice and recommendations. Most often, medical professionals recommended athletes take a substantial amount of time off to let their injuries heal, while coaches encouraged them to continue their participation. One athlete explained that he stopped visiting his therapist, so that he would not need to address this conflict:

It was hard because my athletic therapist is an older lady. She is really experienced and worked with [an Olympian] and stuff, but if you asked any of the coaches here they would say that she is a little bit too cautious. So she wanted me to completely stop swimming, and my coach said that, "No, you are not doing that." And I too said that I am not doing that. And I think that was part of the reason that I stayed away from therapy in the winter-because I said that I cannot take being cradled anymore. "Don't do this. Don't do that." (P6, M-21)

Findings regarding inconsistent direction from support networks are concerning; athletes' decisions to seek out help while recovering from injury is contingent on expectancy beliefs regarding others' expertise (Hoar \& Flint, 2008), while low social support and psychological distress are associated with poorer rehabilitation 
compliance and recovery (Smith, Scott, O'Fallon, \& Young 1990; Taylor \& Taylor, 1997). These findings highlight the importance of coaches and medical practitioners demonstrating expertise in their particular area, while underlining the value of strong communication between coaches and medical practitioners. In particular, medical practitioners should be knowledgeable about each athlete's sport, training program, competition goals, and comprehensive injury history, while coaching staff would benefit from greater understanding of specific injuries and appropriate training modifications, as well as improved ability to determine the point an athlete should remove him or herself from training. Such a collective team approach to rehabilitation would no doubt significantly reduce athletes' frustrations, and could possibly be facilitated through the services of a sport psychologist. Brewer (2007) suggests that while it is logical for sport psychologists to serve as social support providers for injured athletes, there has been very little research examining this possibility. While none of the twelve athletes in this study spoke about the role of sport psychologists in their injury processes, this could be because very few university sport programs in Canada include the services of full-time sport psychologists. However, given sport psychologists' expertise in the areas of providing emotional and psychological support, facilitating injury recovery strategies such as imagery and goal-setting, and fostering optimal coping skills, it is expected that their services could be extremely beneficial.

\section{Limitations and Future Directions}

Given the complex nature of gradual onset or overuse injuries commonly found in swimmers, the study used a retrospective approach among athletes at diverse stages within the injury process. Future researchers may draw upon innovative methodologies such as ethnography and athlete journaling to prospectively tap into athletes' experiences with their networks of support throughout their injury, with a particular focus on key time points (e.g., training through injuries, returning to sport after injuries, consideration of sport withdrawal due to injury). Further, given the study's focus on understanding experiences across a purposefully diverse sample of interuniversity athletes (Miles \& Huberman, 1994), similarities and differences according to demographic or situational variables were not examined. Future work focused on understanding social support according to situational factors such as coach or team may be of interest, given that findings of this study suggested individual participants actually had contrasting experiences throughout different injury processes within their university swimming career. For example, some participants reported both experiences of open communication with their coach, as well as hesitations to communicate openly with their coach. Finally, this study focused on the experiences of 12 interuniversity swimmers in the provinces of Quebec and Ontario, Canada, throughout their injury processes. As such, generalizations to other interuniversity or intercollegiate contexts should be done with caution due to the substantive differences between programs. Future researchers should continue to gain understanding of support networks, exchanges, and appraisals, while examining associations between variables in multiple diverse sociocultural contexts to contribute to generalizable best practices for all athletes, coaches, medical practitioners, parents, and teammates throughout the injury process. 


\section{Conclusion}

This study advances understanding of athletes' social support experiences during the injury process, within the context of Canadian university sport. Athletes underlined many concerning experiences including coaches and teammates being in denial of their injury, shunning them from the team, or pushing them to train through their injury, resulting in athletes feeling uncared for, unsupported, and lacking direction. Despite this, many athletes spoke of feeling cared for by coaches, medical practitioners, teammates, and parents. These findings underscore the importance of comprehensively examining the multiple constructs of social support (Winemiller et al., 1993), as athletes' appraisals of their exchanges with support networks during the injury process held significant weight. Further, findings allude to an altered and complex framework of social resources (Lin, 1986) in the university sport context, with athletes seeking emotional support primarily from coaches, teammates, and medical practitioners, who may not always be in optimal positions to provide this support. In addition, subtle gender differences with regard to athletes' social support experiences with family and teammates underline a need for further investigations across gender. From a practical perspective, findings suggest that sport psychologists could potentially play a critical role in facilitating effective communication between social support networks during the injury process, while other injured athletes may represent an untapped support network for injured athletes within the team environment. In sum, findings serve as a springboard for important further investigations, while offering preliminary insight into some areas of substantive practical importance during university athletes' injury process.

\section{References}

Abgarov, A., Fraser-Thomas, J., \& Baker, J. (2012).Understanding trends and risk factors of swimming-related injuries in varsity swimmers. Clinical Psychology.

Appaneal, R. N., Perna, F. M., \& Larkin, K. T. (2007). Psychological response to severe sport injury among competitive male athletes: A preliminary investigation. Journal of Clinical Sports Psychology, 1, 68-88.

Arnett, J. J. (2000). Emerging adulthood: A theory of development from the late teens through the twenties. The American Psychologist, 55, 469-480. PubMed doi:10.1037/0003066X.55.5.469

Bianco, T. (2001). Social support and recovery from sport injury: Elite skiers share their experiences. Research Quarterly for Exercise and Sport, 72, 376-388. PubMed

Bianco, T., \& Eklund, R.C. (2001). Conceptual considerations for social support research in sport and exercise settings: The case of sport injury. Journal of Sport \& Exercise Psychology, 23, 85-107.

Brewer, B.W. (2007). Psychology of sport injury rehabilitation. In G. Tenenbaum \& R.C. Eklund (Eds.), Handbook of sport psychology (pp. 404-423). Hoboken, N.J.: Wiley.

Bricker, J., \& Fry, M. (2006). The influence of injured athletes' Perceptions of Social Support From ATCs on Their Beliefs About Rehabilitation. Journal of Sport Rehabilitation, $15,156-167$.

Brushoj, C.K., Bak, K., Johannsen, H., \& Fauno, P. (2007). Swimmers' painful shoulder arthroscopic findings and return rate to sports. Scandinavian Journal of Medicine \& Science in Sports, 17, 373-377. PubMed 
Charmaz, K. (2006). Constructing grounded theory: A practical guide through qualitative analysis. Thousand Oaks, CA: Sage.

Christakou, A., \& Lavallee, D. (2009). Rehabilitation from sports injuries: from theory to practice. Perspectives in Public Health, 129, 120-126. PubMed doi:10.1177/1466424008094802

Clark, W. (2009). Kids' Sports. Retrieved June 23, 2012 from www.statcan.gc.ca/pub/aa008-x/2008001/article/10573-eng.htm.

Corbin, J., \& Strauss, A. (2008). Basics of qualitative research. Thousand Oaks, CA: Sage.

Côté, J. (1999). The influence of the family in the development of talent in sports. The Sport Psychologist, 13, 395-417.

Dakof, G.A., \& Taylor, S.E. (1990). Victims' perceptions of support attempts: Which is helpful from whom? Journal of Personality and Social Psychology, 58, 80-89. PubMed doi:10.1037/0022-3514.58.1.80

Flint, F.A. (1998). Integrating sport psychology and sports medicine in research: The dilemmas. Journal of Applied Sport Psychology, 10, 83-102. doi:10.1080/10413209808406379

Fraser-Thomas, J., \& Côté, J. (2008). Understanding adolescents' positive and negative experiences in sport. Paper presented at the annual Sport Canada Research Initiative conference. Gatineau, Canada

Fraser-Thomas, J., Côté, J., \& Deakin, J. (2008). Examining adolescent sport dropout and prolonged engagement from a developmental perspective. Journal of Applied Sport Psychology, 20, 318-333. doi:10.1080/10413200802163549

Gordon, S., Potter, M., \& Ford, I. (1998). Toward a psychoeducational curriculum for training sport-injury rehabilitation personnel. Journal of Applied Sport Psychology, 10, 140-156. doi:10.1080/10413209808406382

Gould, D., Udry, E., Bridges, D., \& Beck, L. (1997). Coping with season ending injuries. The Sport Psychologist, 11, 379-399.

Hardy, C.J., \& Crace, R.K. (1993). The dimensions of social support when dealing with sport injuries. In D. Paragman (Ed.), Psychological bases of sport injury (pp. 121-144). Morgantown, WV: Fitness Information Technology.

Hoar, S. D., \& Flint, F. (2008). Determinants of help-seeking intentions in the context of athletic injury recovery. International Journal of Sport and Exercise Psychology, 6, 157-175. doi:10.1080/1612197X.2008.9671859

Hootman, J. M., Dick, R., \& Agel, J. (2007). Epidemiology of collegiate injuries for 15 sports: Summary and recommendations for injury prevention initiatives. Journal of Athletic Training, 42, 311-319. PubMed

Law, M. P., Côté, J., \& Ericsson, K. A. (2007). Characteristics of expert development in rhythmic gymnastics: A retrospective study. International Journal of Sport and Exercise Psychology, 5, 82-103. doi:10.1080/1612197X.2008.9671814

Lewis-Griffith, L. (1982). Athletic injuries can be a pain in the head too. Women's Sport, 4, 44.

Lin, N. (1986). Conceptualizing social support. In N. Lin, A. Dean, \& W.M. Ensel (Eds.), Social support, life events, and depression (pp. 17-30). Orlando, FL: Academic Press.

McMaster, W.C. (1996). Swimming injuries: An overview. Sports Medicine (Auckland, N.Z.), 22, 332-336. PubMed doi:10.2165/00007256-199622050-00006

Miles, M.B., \& Huberman, A.M. (1994). Qualitative data analysis. An expanded sourcebook. Thousand Oaks, CA: Sage.

Newcomer, R. R., \& Perna, F. M. (2003). Features of posttraumatic distress among adolescent athletes. Journal of Athletic Training, 38, 163-166. PubMed

Nixon, H. (1994). Coaches views of risk, pain, and injury in sport, with special reference to gender difference. Sociology of Sport Journal, 11, 79-87.

Patton, M.Q. (2002). Qualitative research and evaluation methods (3rd ed.). Thousand Oaks, CA: Sage Publications. 
Ptacek, J.T., Smith, R.E., \& Dodge, K.L. (1994). Gender differences in coping with stress: When stressor and appraisals do not differ. Personality and Social Psychology Bulletin, 20, 421-430. doi:10.1177/0146167294204009

Ropponen, A., Levalahti, E., Simonen, R., Videman, T., \& Battie, M.C. (2001). Repeatability of lifetime exercise reporting. Scandinavian Journal of Medicine \& Science in Sports, 11, 185-192. PubMed doi:10.1046/j.1524-4725.2001.110309.x

Sarason, B.R., Sarason, I.G., \& Pierce, G.R. (1994). Relationship-specific social support: Toward a model for the analysis of supportive interactions. In B.R. Burleson, T.L. Albrech, \& I.G. Sarason (Eds.), Communication of social support (pp. 91-112). Thousand Oaks, CA: Sage.

Shumaker, S.A., \& Brownell, A. (1984). Toward a theory of social support: Closing conceptual gaps. The Journal of Social Issues, 40, 11-36. doi:10.1111/j.1540-4560.1984. tb01105.x

Schwarzer, R., \& Leppin, A. (1991). Social support and health: A theoretical and empirical overview. Journal of Social and Personal Relationships, 8, 99-127. doi:10.1177/0265407591081005

Smith, A.M., Scott, S., O'Fallon, W., \& Young, M. (1990). Emotional responses of athletes to injury. Mayo Clinic Proceedings, 65, 38-50. PubMed

Statistics Canada. (2010). The Daily. Canadian Community Health Survey. Retrieved June 18, 2010 from http://www.statcan.gc.ca/daily-quotidien/100615/dq100615b-eng.html.

Taylor, J., \& Taylor, S. (1997). Psychological Approaches to Sports Injury Rehabilitation. Gaithersburg, MD: Aspen Press.

Tracey, J. (2011). Self-cultivation and meaning through the experience of injury rehabilitation: A case study of two female basketball players. Journal of Excellence, 15, 28-39.

Tracey, J. (2003). The emotional response to the injury and rehabilitation process. Journal of Applied Sport Psychology, 15, 279-293. doi:10.1080/714044197

Udry, E. (1997). Coping and social support among injured athletes following surgery. Journal of Sport \& Exercise Psychology, 19, 71-90.

Vaux, A. (1988). Social support: Theory, research, and intervention. New York: Praeger.

Winemiller, D.R., Mitchell, M.E., Sutcliff, J., \& Cline, D.J. (1993). Measurement strategies in social support: A descriptive review of literature. Journal of Clinical Psychology, 49, 638-648. PubMed doi:10.1002/1097-4679(199309)49:5<638::AIDJCLP2270490505>3.0.CO;2-7

Yang, J., Peek-Asa, C., Lowe, J.B., Heiden, E., \& Foster, D.T. (2010). Social support patterns of collegiate athletes before and after injury. Journal of Athletic Training, 45, 372-379. PubMed doi:10.4085/1062-6050-45.4.372

Young, K., White, P., \& McTeer, W. (1994). Body talk: Male athletes reflect on sport, injury and pain. Sociology of Sport Journal, 11, 175-194. 